\title{
La ocupación empresarial de territorio agrícola de la Ciénaga de Chapala, Michoacán, México
}

Juan Manuel Catalán Romero ${ }^{a}$ - Francisco Covarrubias Villab - Ángela Samara Vidal Cejac

RESUMEN: El objetivo de este trabajo es mostrar el proceso creciente de ocupación del suelo agrícola de la ciénaga de Chapala, agudizado a partir de principios del siglo XXI. El método seguido fue el siguiente: delimitación del objeto de investigación, diseño del esquema de investigación, identificación de fuentes de información, diseño de instrumentos de investigación de campo, análisis y fichado de fuentes de información y exposición de

\footnotetext{
a Doctor en Pedagogía por el Centro de Estudios de Posgrado del Bajío en León, Guanajuato. Biólogo por la Escuela Nacional de Ciencias Biológicas del IPN y profesor investigador del Centro Interdisciplinario para el Desarrollo Integral Regional en Jiquilpan, Mich., desde 1982. ORCID: http://orcid.org/0000-0002-3168-8966. Contacto: jmcatalan@ipn.mx.

b Licenciado, Maestro y Doctor en Ciencia Política, Universidad Autónoma de México. Miembro del Sistema Nacional de Investigadores desde 1993. Autor de 38 artículos en revistas especializadas y de 24 libros y 13 capítulos en libros. Actualmente Profesor de Educación Superior Titular "C" Tiempo Completo, Instituto Politécnico Nacional. ORCID: http://orcid.org/0000-0003-1728-0080. Contacto: pancheco@prodigy.net.mx.

${ }^{c}$ Licenciada en Arquitectura por el Instituto Tecnológico de México en Jiquilpan y Maestrante de la Maestría en Producción Agrícola Sustentable en el CIIDIR Unidad Michoacán del Instituto Politécnico Nacional. Contacto: ansavice@gmail.com.
}

Recepción: 31/octubre/2019 
Sección Especial - Territorios, Sustentabilidad, Cultura y Transformación de Espacios

resultados. Se encontró que principalmente a los lados de las carreteras Villamar-Jiquilpan, Jiquilpan-Briseñas, Briseñas-Vistahermosa y Vistahermosa-Ixtlán y en sitios cercanos a éstas, se ha instalado una gran cantidad de empresas. Lo encontrado forma parte del proceso de incorporación de la región a la dinámica del capitalismo transnacional, ya que estas empresas están orientadas a la exportación o expenden productos de empresas transnacionales.

Palabras clave: ciénaga de Chapala, agroindustria, territorio, agricultura, ganadería

ABSTRACT: The objective of this work is to show the growing process of occupation of the agricultural land of the Chapala swamp, sharpened from the beginning of the 21st century. The method followed was the following: delimitation of the research object, design of the research scheme, identification of information sources, design of field research instruments, analysis and filing of information sources and presentation of results. It was found that mainly on the sides of the Villamar-Jiquilpan, Jiquilpan-Briseñas, Briseñas-Vistahermosa and Vistahermosa-Ixtlán roads and in places near to them, a large number of companies have been installed. The findings are part of the process of incorporating the region into the dynamics of transnational capitalism since these companies are export-oriented or sell products of transnational companies.

Keywords: Chapala swamp, agroindustry, territory, agriculture, livestock

\section{Introducción}

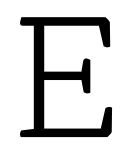

1 presente trabajo es un producto parcial del proyecto de investigación denominado: La transformación del paisaje agrario en la Ciénaga de Chapala, Clave: SIP-20194950 financiado por el Instituto Politécnico Nacional, México.

El lago de Chapala es un vaso regulador de las descargas provenientes principalmente de los ríos Lerma y Duero y su salida por el río Santiago. Con la finalidad de utilizar su suelo para actividades agrícolas, el lago fue objeto de desecación parcial, primero por la reducción de alrededor de tres metros de la desembocadura del lago en el río Santiago y después por la construcción del bordo de Maltaraña.

La zona desecada se conoce como "ciénaga de Chapala" y fue vendida a hacendados y rancheros de la región y convertida en zona productora de granos. A partir de la reforma al 
artículo 27 constitucional de 1992, se ha acelerado la instalación de empresas de todo tipo, transformando los procesos de producción agrícola y modificando el uso agrícola del suelo.

La tendencia apunta hacia el incremento de terrenos con acolchados, túneles e invernaderos dedicados a la producción agrícola para la exportación; el arrendamiento de parcelas ejidales a empresas agroindustriales y; la proletarización de la inmensa mayoría de los pobladores de la región.

\section{La ciénaga de Chapala}

La ciénaga de Chapala colinda al norte con el Lago de Chapala y con el río Lerma; al noroeste con el río Duero, en el tramo que comprende los poblados de Ibarra y Cumuato; al este con Venustiano Carranza y los cerros de Pajacuarán y Guaracha; al sur con las poblaciones de Jiquilpan, Totolán, Emiliano Zapata y Villamar y; al oeste con Sahuayo y La Palma. (Rangel, 2005: 324-325)

Dice la Comisión Nacional de Irrigación: "La Ciénega de Chapala se encuentra situada en la esquina NE. del Estado de Michoacán y SE. del de Jalisco, en la parte desecada del lago del mismo nombre, como a 120 kilómetros al SE. de la ciudad de Guadalajara, Jal., y a 2 kilómetros al sur de la ciudad de La Barca, Jal. En las estribaciones norte de la sierra que limita la parte sur y SE. de la ciénega se encuentran situados el pueblo de Pajacuarán, las ciudades de Jiquilpan y Sahuayo y la tenencia de La Palma, Mich. [...] Está limitada al norte por el dique de protección que rectifica al río Duero; al S. y SW. por la sierra de Pajacuarán, que es la prolongación de la serranía que viene desde los cerros de Tangancícuaro y Patámban; al E. por el río Duero, antes de ser rectificado y al W. por los diques de protección que limitan al lago de Chapala". (Comisión, 1932: 9-10)

Al nivel actual del lago de Chapala se le asignó una altitud de 1,524.60 msnm. pero, con base en el estudio de campo realizado, consistente en la medición de la altitud por el contorno de la ciénaga, en puntos en los que existen evidencias (atracaderos) o memoria histórica de los pobladores de que hasta ahí llegó el nivel del lago, se considera que antes de la desecación alcanzaba los 1,532 msnm.

La acción sobre el medio ambiente ejercida por los pobladores prehispánicos asentados en ese territorio se limitó a la construcción de caminos por la ribera del lago y tamandas (caminos flotantes construidos con hierbas acuáticas) por zonas pantanosas por las que caminaban. La 
Sección Especial - Territorios, Sustentabilidad, Cultura y Transformación de Espacios

agricultura fue una actividad complementaria pues su subsistencia se basaba en la pesca, la caza y la recolección.

Durante la Colonia la actividad ganadera trashumante surge como un instrumento de privatización de las tierras indígenas, "generándose progresivamente complejos mecanismos de articulación social e institucional en defensa de privilegios de grupos, sin prever consecuencias ecológicas" (Dávila, 2014: 189). El régimen de propiedad del suelo inició con la denominada "encomienda". En ella, el indígena conserva sus vínculos de identidad y pertenencia, y establece con el encomendero una relación temporal de mano de obra no especializada sin retribución.

Rodríguez Demorizi denomina a la encomienda como "un derecho concedido por merced real a los beneméritos de Indias para recibir y cobrar para sí los tributos de los indios que se les encomendasen por su vida y la de un heredero, con rango de cuidar de los indios en lo espiritual y temporal y defender las provincias donde fueren encomendados" (1971: 25-26). Hasta el 20 de noviembre de 1542 que se promulgaron las "Leyes y ordenanzas nuevamente hechas por su Majestad para la gobernación de las Indias y buen tratamiento y conservación de los indios", que mejoran las condiciones de los naturales de América, excluyendo de la asignación de encomiendas a oficiales reales, órdenes religiosas, hospitales y cofradías.

Hernán Cortés en 1524 otorga en encomienda a Juan de Albornoz los pueblos de Sahuayo, Caro, Guaracha, Pajacuarán, Jacona y Chaparaco, pero, más adelante se otorga por el mismo Cortés, esta encomienda al Capitán Gonzalo de Sandoval, que a su muerte en 1528 la hereda a su primo Juan de Sandoval. Los sitios donde agostaban temporalmente los rebaños aportaron las bases para la apropiación privada del suelo. El término "estancia” en la Nueva España se relaciona con una regularización de algunos rebaños o hatos que hasta entonces han venido pastando donde se presenta la oportunidad. (Chevalier, 1976: 122)

Sandoval y Paleta (2015: 132) sostienen que hay relaciones desiguales entre hacendados, peones acasillados y comunidades indígenas para el acceso a la tierra y al agua. Estas relaciones desiguales fueron la base para que, después de la desecación de la Ciénega, se configuraran nuevas relaciones de poder entre el Estado, como propietario de los bienes nacionales y las poblaciones dedicadas a la pesca y la agricultura y las estancias de ganado mayor y menor (reses, caballos, mulas, burros, ovejas y cerdos).

Dice Dávila Moreno que "las dotaciones privadas de los pastos originaron la formación de estancias como sitios definitivos para el hombre y su ganado. El virrey Antonio de Mendoza 


\section{Sección Especial - Territorio, Sustentabilidad, Cultura y Transformación de Espacios}

(1490-1552) extendió entre marzo y mayo de 1550 las primeras mercedes de tierras, en caballerías y estancias, con plenitud de derechos de propiedad y transmisión hereditaria. Una real cédula y sobrecédula ratificaron la política ganadera al señalar que el Rey se haría cargo de los daños que a los indígenas generara el ganado, especialmente el vacuno". (Dávila, 1989: 71)

El proceso de ocupación de la tierra desde la conquista hasta mediados del siglo XVIII deriva del aumento de la población y de la implementación sistemática de actividades agropecuarias. Sin embargo, para los indígenas, la cría y engorda de ganado no era una opción ocupacional dado que quedó reservada a los españoles. El crecimiento territorial y económico de las haciendas en esta región, fue motivado por el cultivo de cereales (como el trigo europeo) y la ganadería extensiva con el objeto de proveer a grandes ciudades de carne de res, borrego y cerdos y a los complejos mineros de burros y mulas.

Las haciendas son resultado de la expansión de la ganadería por el territorio y el primer ejemplo de la formación de los latifundios. La hacienda más destacada en la región de la Ciénaga es la de Guaracha. La hacienda de Cojumatlán que formaba parte de la hacienda del Monte, fue vendida a Guaracha en 1625 (González, 1979: 282-283); la de La Palma, que inició como estancia de ganado mayor en 1596, fue vendida en 1655 a Guaracha (González, 1979: 283); las haciendas de San Simón y San Nicolás en la parte baja del valle de Zamora, colindantes con Pajacuarán y Chavinda integradas a Guaracha en 1596 (Montes, 1999: 8); la hacienda del Platanal que surgió de las mercedes concedidas a Juan de Salceda y Pedro de Salceda Andrade entre 1593 y 1596 y que también fue integrada a la hacienda de Guaracha. (Montes, 1999: 8)

En 1867 se crea la Compañía de Navegación de Vapor en el Lago de Chapala y en 1868 inicia los servicios de transportación en la ruta Chapala-La Barca-Ocotlán-Jamay-La PalmaTuxcueca. (Tortolero, 2002)

El lago tenía un poco más de 150 mil hectáreas; en la medida en que avanzaba la temporada de secas, y cuando las lluvias escasean durante varios años, el nivel bajaba poniendo al descubierto 54,358 hectáreas (Comisión, 1932: 9). Los terrenos que iban quedando al descubierto eran objeto de disputa entre hacendados y entre éstos y las comunidades indígenas. (Véase Figs. 1 y 2)

El aumento de la demanda de granos a finales del siglo xix provocó las primeras acciones para desecar el lago y se dinamitaron alrededor de tres metros de altura de la desembocadura del lago en el río Santiago. Para regar el terreno desecado por la baja de esos tres metros del nivel de las aguas, fue desviado el cauce del río Duero que iba por los bajos de la Luz y Pajacuarán, 


\section{Sección Especial - Territorios, Sustentabilidad, Cultura y Transformación de Espacios}

haciéndolo desembocar en el río Lerma. Después, el gobierno de Porfirio Díaz autorizó la construcción del bordo de Maltaraña, para desecar las cincuenta mil hectáreas que quedaban al descubierto en los periodos de sequía prolongada, y dedicar esos terrenos a la agricultura. La construcción del bordo fue acordada en 1900 y concluida en 1912 (Tortolero, 2002); el terreno desecado quedó en manos de la Compañía Hidroeléctrica e Irrigadora de Chapala, propiedad de Manuel Cuesta Gallardo.

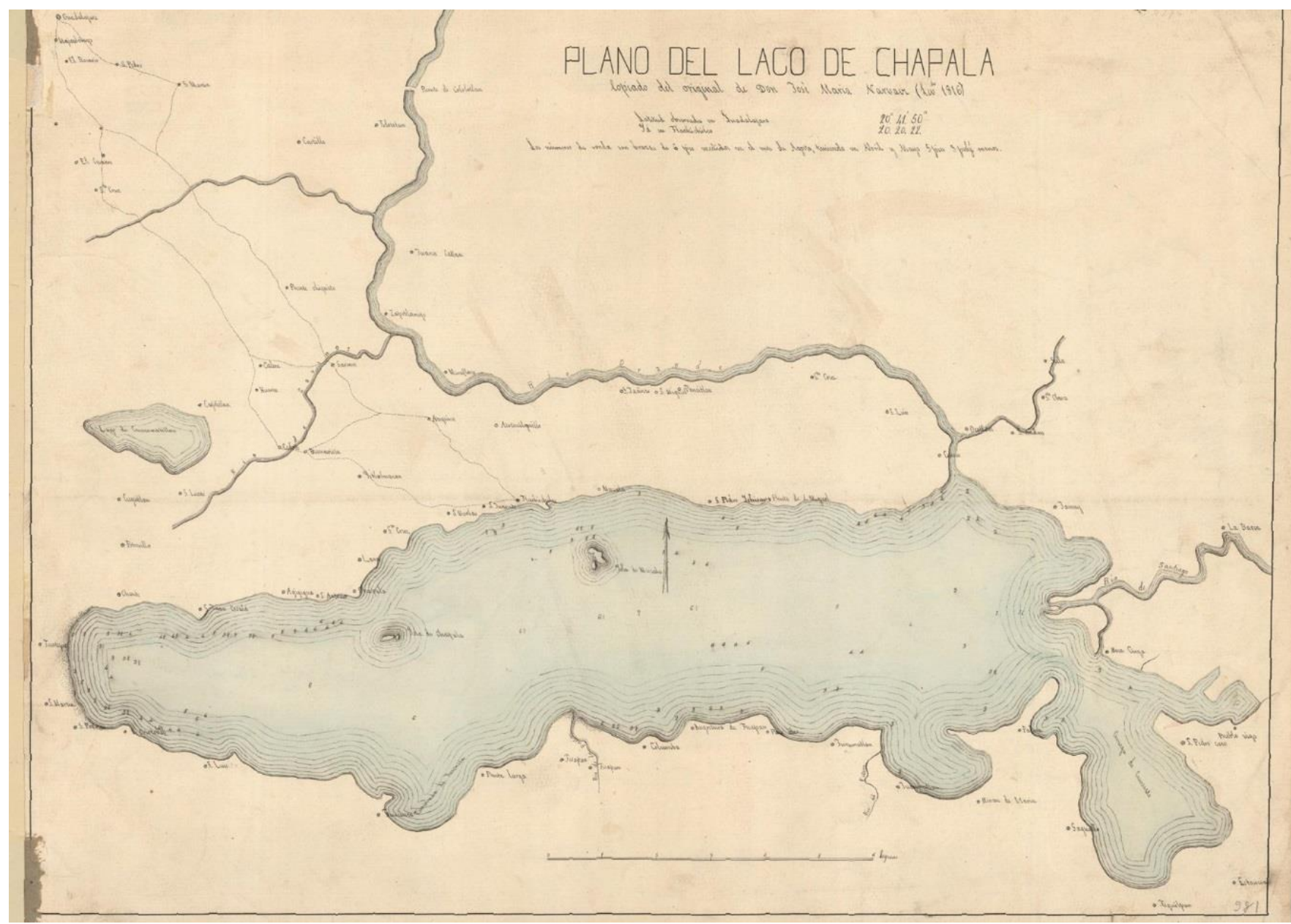

Figura 1. Plano del Lago Chapala. 1816. Fuente: José María Narváez. Ubicación: MMOB, CMOB, Jalisco V01 No de control 381 papel algodón sobre tela (CEA Jalisco). http://images.app.goo.gl/ib6d9hayfQwCzQZTA

Fuente: José María Narváez. Ubicación: MMOB, CMOB, Jalisco V01 No de control 381 papel algodón sobre tela (CEA Jalisco). http://images.app.goo.gl/ib6d9hayfQwCzQZTA 


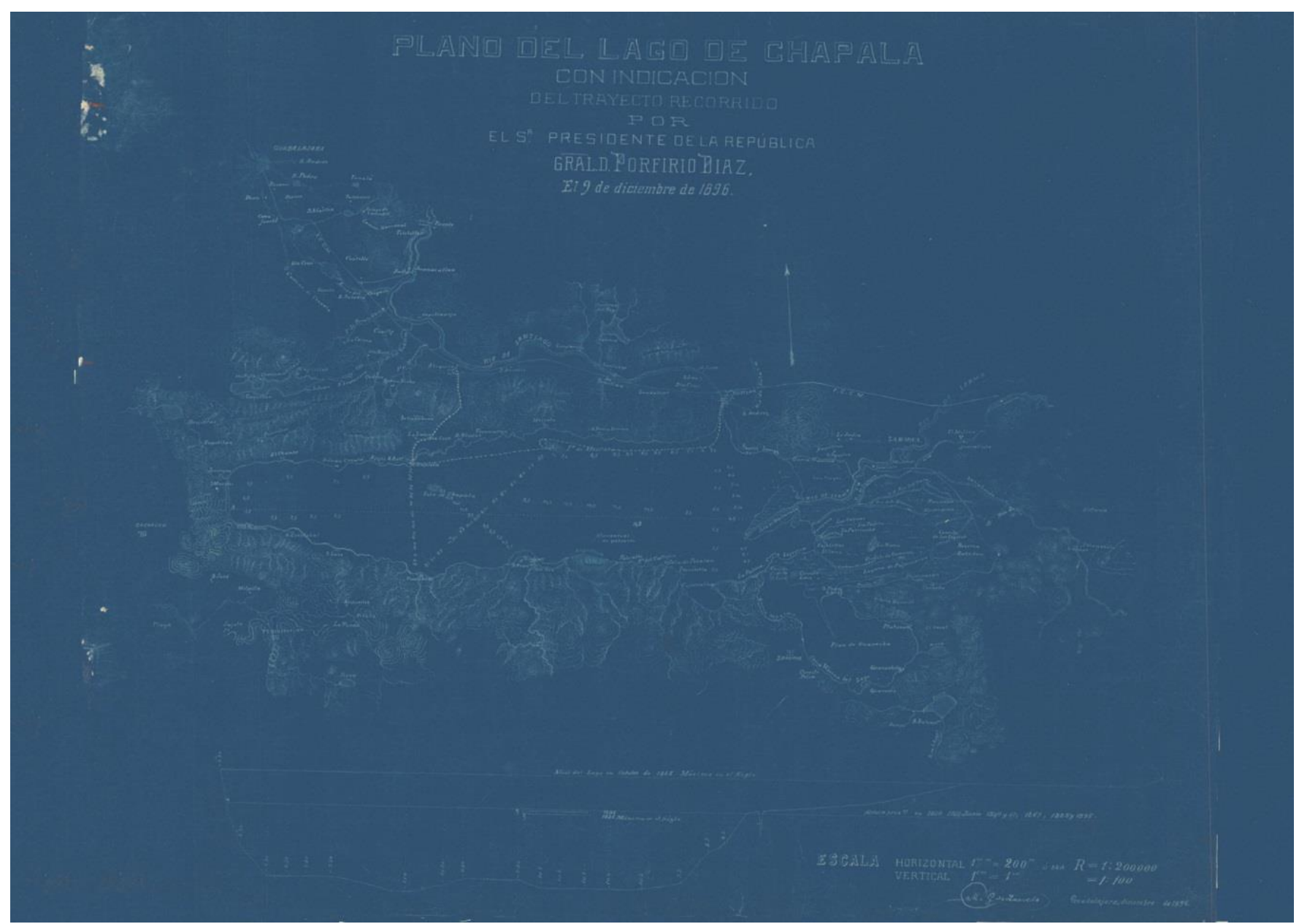

Figura 2. Plano del Lago de Chapala y Río Santiago con el Dique de Maltaraña. Siglo xix. Fuente: Mapoteca.

SIAP.gob.mx/index.php/ctg-jal-m9-v2-0099

Estas tres grandes acciones proyectadas, iniciadas y ejecutadas a finales del siglo XIX e inicios del XX impactaron fuertemente la configuración territorial, social y económica de la región: i) la dinamitación de la boca del río Santiago y construcción de la hidroeléctrica, ii) la modificación del cauce del río Duero y, iii) la construcción del bordo de Maltaraña. La desecación parcial del lago impidió el transporte de mercancías embarcadas en Sahuayo y de ahí trasladadas a Ocotlán o a Chapala. (Véase Fig. Núm. 3). Los terrenos desecados fueron vendidos a hacendados y rancheros, pero, en la década de los años treinta, Cárdenas realizó un masivo reparto de tierras que dejó la mayor parte de la ciénaga en manos de comunidades ejidales (González, 1979: 374-375; Montes, 1991: 110-131), bajo un régimen jurídico que prohibía la cesión, la venta y el arrendamiento de parcelas ejidales, aunque esto sucediera informalmente y se legitimara después en las investigaciones de usufructo parcelario. 
Sin embargo, durante el gobierno de Carlos Salinas de Gortari en el año de 1992, fue reformado el artículo 27 constitucional y creadas las condiciones jurídicas para convertir la parcela ejidal en propiedad individual, y para cambiar al régimen de propiedad privada.

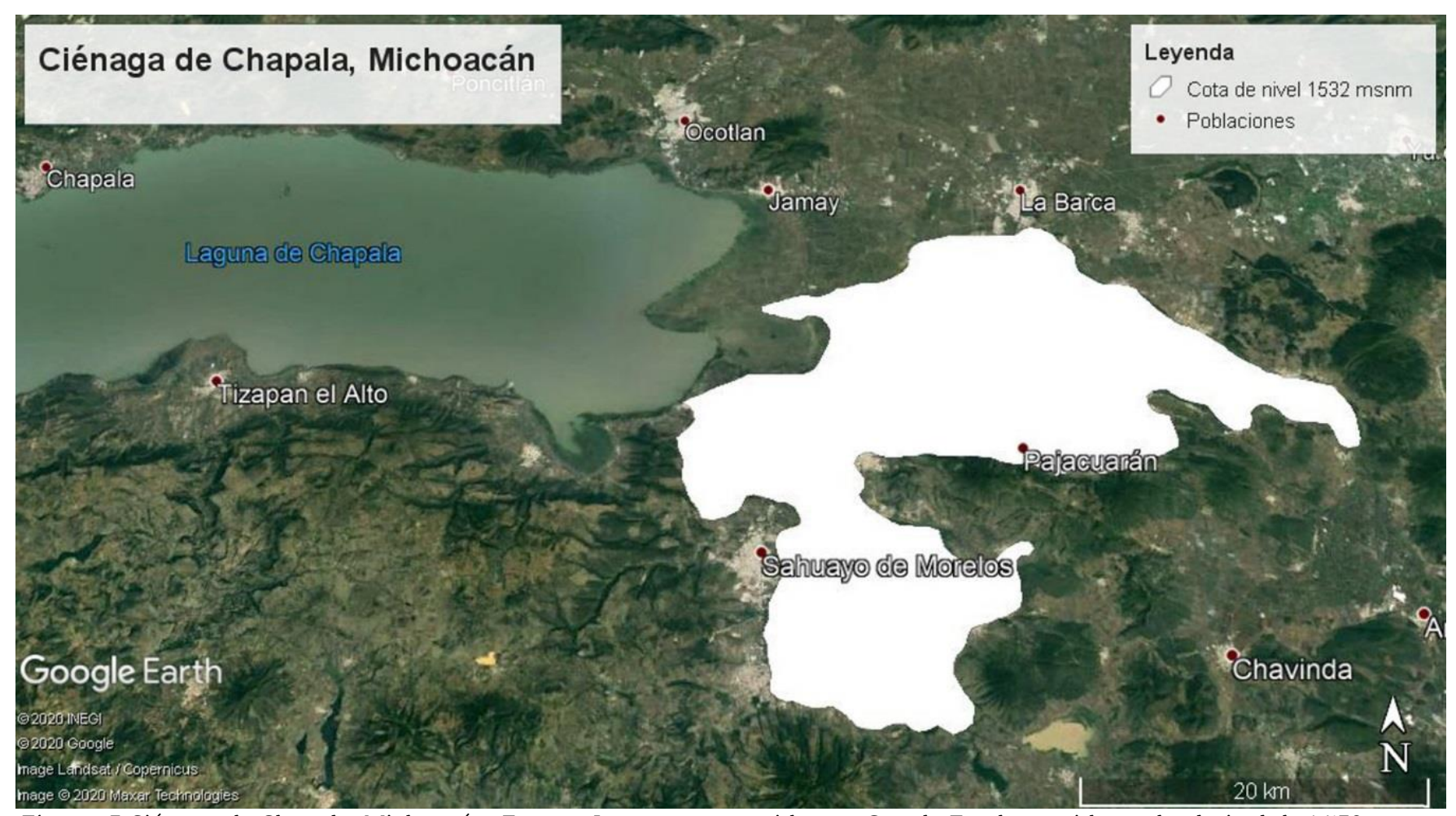

Figura. 3. Ciénaga de Chapala, Michoacán. Fuente: Imagen construida con Google Earth considerando el nivel de 1,532 msnm.

Desde finales del siglo XX el arrendamiento y venta de parcelas ejidales es un fenómeno generalizado en la Ciénaga de Chápala. Los pequeños agricultores y los empresarios agrícolas compran y rentan parcelas ejidales y los ejidatarios y sus hijos van transitando a jornaleros agrícolas. Actualmente, el cultivo de diez hectáreas o menos es incosteable por el alto precio de la maquinaria y de los insumos agrícolas; esto obliga a los ejidatarios con menos de diez hectáreas a hipotecar, arrendar o vender sus tierras y convertirse en jornaleros. Muchos de ellos recurren a la migración en México y a los Estados Unidos. (Vargas González, 1993)

\section{La agroindustria}

A los lados de las carreteras Jiquilpan-Sahuayo y Sahuayo-San Pedro Caro, están proliferando empresas de diversos giros: chatarreras, procesadoras de lácteos, mueblerías (fabricación y 


\section{Sección Especial - Territorio, Sustentabilidad, Cultura y Transformación de Espacios}

exhibición), bodegas de semillas, agroquímicos y productos veterinarios, viveros de plantas de ornato y árboles frutales, concesionarias de automóviles, empacadoras, congeladoras y procesadoras de productos agrícolas, etc. Por una brecha que entronca con la carretera Jiquilpan-Sahuayo se llega al Complejo Administrativo y Policial C5 Jiquilpan, recientemente nombrado cuartel de la Guardia Nacional.

Vargas González reporta que son cuarenta las empresas agroindustriales establecidas en el Distrito de Riego No. 24 (ciénaga de Chapala) en 1979: 25 en Sahuayo, 13 en Jiquilpan y 2 en Venustiano Carranza. Éstas se agrupan en: 13 empresas de leche, queso y crema; 4 empacadoras de carne; 1 molino de harina, 14 fabrican muebles y artículos de madera; 13 producen sombreros de palma; 3 de forrajes y alimentos para ganado y 3 empacadoras de alimentos. Las hay de capital estatal (LICONSA), empresas mixtas y el resto de capital privado. (Vargas, 1993)

Localizadas por medio del DENUE-INEGI, actualmente existe: una macroempresa lechera (LICONSA); 1 empresa lechera mediana (Productos Lácteos Flores, S. A. de C.V.) y; 27 microempresas lecheras. Empacadoras de carne: una macroempresa, SuKarne y 4 microempresas de empacado y embutidos. El molino de harina de Jiquilpan, que ahora forma parte del grupo Kasto. Fabricantes de muebles en su mayoría microempresas (74) y dos empresas medianas en Jiquilpan y Sahuayo. Las empresas de sombreros de todo tipo son 9 y todas se ubican en Sahuayo. Forrajeras y bodegas de alimentos para animales sólo se registran cuatro, pero pudieran ser un poco más. Empacadoras de alimentos se considera la existencia aproximada de tres.

En los últimos 20 años la Ciénaga de Chapala se ha convertido en receptáculo de empresas de diferentes ramas económicas. Hay empresas dedicadas a la compra y a la venta de productos agropecuarios que fueron creadas entre los años 1960 y 2000, otras de carácter agroindustrial de más reciente instalación y otras de ramas de la economía no directamente vinculadas al campo. Entre las empresas agroindustriales se destacan tres: Natural Fruits, S. A. de C. V., Ganadería Integral Monarca, S. A. de C. V. más conocida como SuKarne y Agropecuaria Trigón, S. A. de C. V., empresa oriunda de Jalisco que ha puesto una unidad productora en territorio de la ciénaga michoacana. (Ver Fig. 4)

Natural Fruits es una empresa congeladora de fresa, durazno y otras frutas, que tiene sus inicios en los años sesenta financiada por el Banco Nacional de Crédito Ejidal que, como la mayoría de las empresas ejidales creadas en la región (granjas porcícolas, establos vacunos, estanques piscícolas, cooperativas diversas), tuvieron una administración deficiente y corrompida (Buenrostro, 2019; Sánchez, 2019). Esta empresa empacadora se instaló fuera del 
Sección Especial - Territorios, Sustentabilidad, Cultura y Transformación de Espacios

poblado de San Pedro Caro o Venustiano Carranza y dio empleo a personas de toda la región, destacando la contratación masiva de mujeres por su habilidad manual, dedicación y fácil control laboral. Quebró la empresa siendo propiedad del Banco Nacional de Crédito Rural y fue privatizada en 2002. Hoy día está inmersa en la mancha urbana, da empleo a lugareños y es empresa privada.

La empresa Agropecuaria Trigón, S. A. de C. V. inicia sus actividades en Tototlán, Jalisco en 1992. Después crea en La Barca, Jalisco Agro Trigón, S. A. de C. V. y en el correr de esta década establece incubadoras, sucursales de venta, un rastro de pollo y uno de cerdo, incursiona en la cría de ganado porcino y ovino. Originalmente fue creada para la producción de huevo y alimentos balanceados para el ganado. La estación Trigón (incluye una estación de serviciogasolinera), establecida en el municipio de Venustiano Carranza, Michoacán, abarca aproximadamente 15.7 hectáreas y emplea algunas decenas de trabajadores de sexo masculino y femenino. Sus productos son pollo entero (rostizado/blanco), huevo en caja de 360, cerdo en pie, borrego en pie, ganado bovino en pie, gallina reproductora en pie, gallina ligera en pie y como subproductos, harina de carne, gallinaza y pollinaza.

Ganadería Integral Monarca, S. A. de C. V., perteneciente al consorcio SuKarne, tiene una planta instalada en Vista Hermosa, Michoacán denominada la Planta TIF 431. Dice su página en Internet que en el año de 2016 SuKarne vendió 640 mil toneladas de carne, que llegaron al consumidor final por medio de más de 40 mil puntos de venta a consumidores de cuatro continentes; cuenta con 700 mil cabezas de ganado en engorda permanente y un millón 600 mil cabezas de ganado procesados en instalaciones inspeccionadas por el gobierno federal. Cuenta con más de cien mil ganaderos y agricultores que proporcionan el ganado y los productos agrícolas (algo muy relevante y observado en la región), procesa un millón 500 mil toneladas de alimento para ganado y cuenta con seis plantas de procesamiento en México y una en Nicaragua. Tiene una filial llamada RENFRO que se especializa en la producción secundaria y venta de harina de carne y sebo de grado alimenticio.

La revista Mundo Ejecutivo indica que, en México, entre 2012 y 2016, siete empresas se quedan con la preferencia de quienes compran carne de res en un 46-50\%; para la carne de cerdo de 51-53\%; y para pollo en 41-42\% del mercado, estas empresas cadenas de procesamiento y venta son: SuKarne, Maxi Carne, El Jarocho Carnicerías, Carnemart, BIF, Cafisu y Carnes Ramos. (Redacción, 2017)

El Consejo Mexicano de la Carne en su compendio estadístico de 2018 menciona que se consume a nivel mundial 65 kg per cápita, posicionando a México en el sexto lugar con más 


\section{Sección Especial - Territorio, Sustentabilidad, Cultura y Transformación de Espacios}

de 8.5 millones de toneladas de carne de res, cerdo y pollo consumidas al año —con el 3.2\% del consumo mundial de carne-y un importante productor de cárnicos, ocupando la séptima posición con más de 6.7 millones de toneladas producidas anualmente. El consumo interno en 2018 de 6.9 millones de toneladas comprende 48\% sólo de pollo, del cual se exportan 2.3 millones de toneladas (Consejo, 2018).

La planta Vista Hermosa se inauguró en el año 2005 y hoy día ocupa una superficie de alrededor de 383 hectáreas, que supera la superficie ocupada por todo el poblado. Cuenta permanentemente con un hato de 104,000 cabezas de ganado y emplea personal de sexo masculino o femenino de toda la región. Compite fuertemente por la contratación de personal con empresas agroindustriales de frutillas, con campañas agresivas de contratación de personal. El estiércol generado por el ganado es composteado y su olor y las partículas suspendidas en el aire generan malestar en los pobladores de Vista Hermosa. (Véase Fig. Núm. 4).

El Complejo Administrativo y Policial C5 Jiquilpan, inaugurado a inicios del año 2018, alegóricamente definido como un complejo que "terminará con los remanentes delincuenciales, garantizará la seguridad y generará condiciones propicias al desarrollo social, económico y turístico" (Redacción, 2018). Como ésta se han construido otras unidades en diferentes lugares del estado de Michoacán que enfrentan problemas de delincuencia y de atención administrativa. En esta nota también se menciona que estará equipado para recibir a 400 oficiales en sus dormitorios y que albergará un centro estatal de coordinación e inteligencia (C5i) que monitoreará a once municipios. También se menciona —aunque hasta la fecha no hay indicios de estar operando en el sitio-, que ahí se instalará una unidad administrativa en la que se ofrezcan servicios de Registro Civil, Recaudación de Rentas, Catastro, Registro Público de la Propiedad, Secretaría de Desarrollo Rural y Agroalimentario. El Complejo ocupa aproximadamente 3.72 hectáreas y se encuentra en la parte baja del llamado Cerrito Pelón, relativamente cerca de una pequeña comunidad llamada Francisco Sarabia (Redacción, 2018). (Véase Fig. Núm. 5). 


\section{Sección Especial - Territorios, Sustentabilidad, Cultura y Transformación de Espacios}

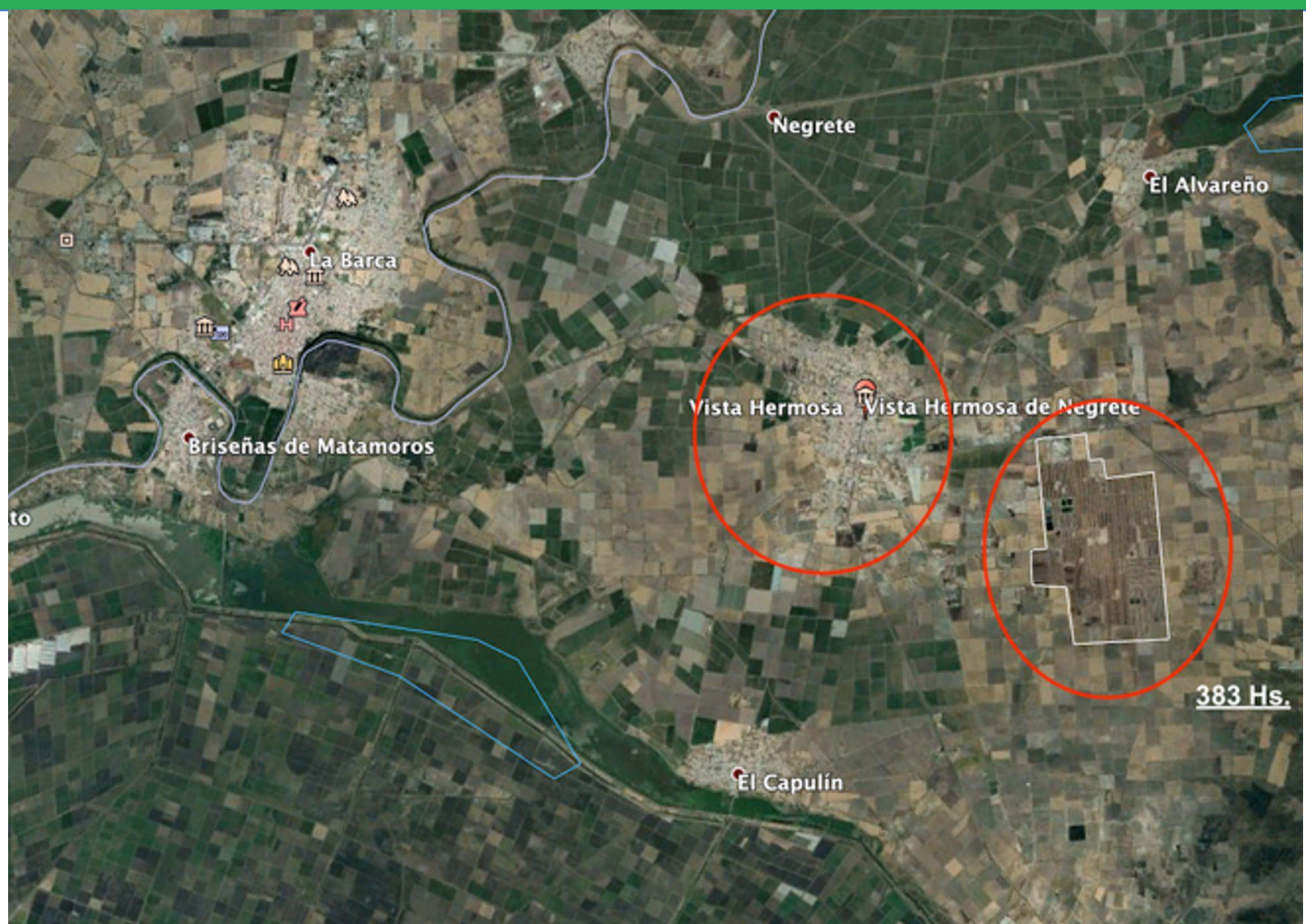

Figura 4. Área y territorio que ocupa Ganadería Integral Monarca S. A. de C. V.

En Vista Hermosa, Mich. 


\section{Sección Especial - Territorio, Sustentabilidad, Cultura y Transformación de Espacios}

Figura Núm. 5

El complejo administrativo y policial C5 de Jiquilpan

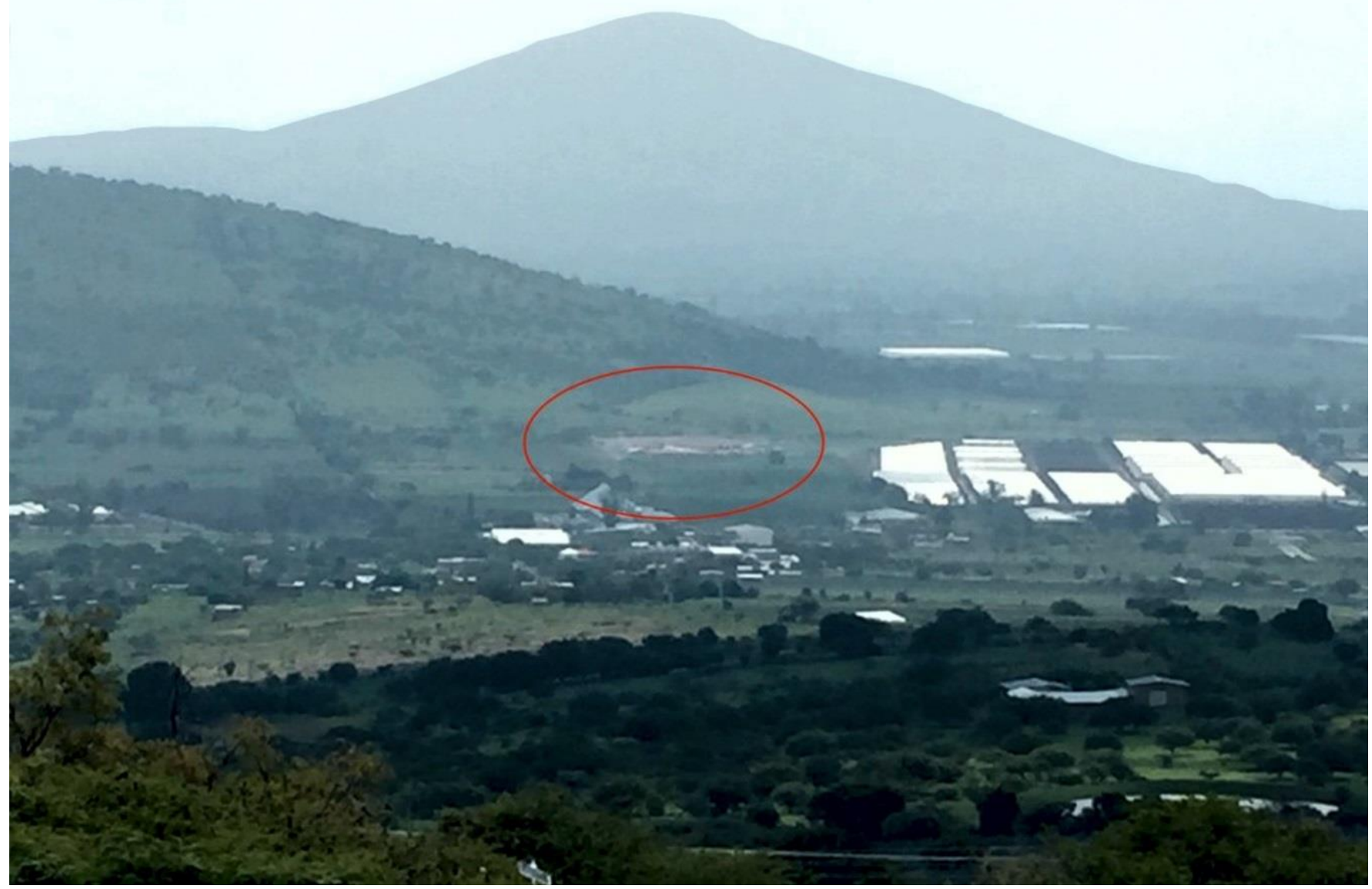

Figura 5. El complejo administrativo y policial C5 de Jiquilpan. Fuente: Foto del autor

La expresión más reciente de la ocupación empresarial de suelo agrícola es el proyecto de instalación de una central de generación de energía eléctrica por radiación solar, que la empresa Gruenebiz implementa en terrenos de Sahuayo, Cotijarán, La Palma y Ojo de Agua sobre parcelas ejidales y pequeñas propiedades, que mediante contrato por 30 años arrendará en los municipios de Sahuayo, Venustiano Carranza y Villamar. Se habla de un total de 2,200 hectáreas arrendadas, y de un pago de 1,300 dólares al año por hectárea. (Dirección, 2019) 


\section{Conclusiones}

El cambio de uso del suelo agrícola de la Ciénaga de Chapala para fraccionamientos y especulación inmobiliaria es un fenómeno estudiado. Sin embargo, la ocupación de terrenos agrícolas o ganaderos con fines industriales, comerciales o de servicios ha sido menos estudiada y se trata de un fenómeno históricamente reciente.

La presencia de empresas agroindustriales en la ciénaga de Chapala y en el Valle de Zamora ha abatido el desempleo, ha incorporado masivamente a la mujer al mercado de trabajo y ha generado escasez de mano de obra para los pequeños agricultores de la región.

Cerca de las carreteras de la ciénaga de Chapala y por sus costados, se están instalando empresas de todo tipo, vinculadas en su mayoría a capitales trasnacionales. Cada vez es mayor la superficie destinada al cultivo de frutillas y hortalizas de exportación, así como a la producción de carne.

Se ha constatado cómo los terrenos donados para la construcción de tecnológicos o universidades en la región, se encuentran en zonas con pendiente pronunciada y alejados de los núcleos poblacionales. En el caso de complejos agroindustriales, en cambio, la instalación se realiza en sitios que cuentan con servicios de transporte de pasajeros, caminos, agua y electricidad.

\section{Referencias}

Buenrostro Álvarez, F. (2019). Entrevista. 10 de agosto de 2019.

Chevalier, F. (1976). La formación de los latifundios en México. México: FCE.

Comisión Nacional de Irrigación. (1932). Estudio Agrícola-Económico de la Ciénega de Chapala. Unidad de Riego Número 4. "Proyecto de Los Corrales." México: Cultura.

Consejo Mexicano de la Carne. (2018). Compendio Estadístico 2018. Recuperado de: https://bit.ly/34VsOMe.

Dávila Moreno, M. E. N. (2014). "El surgimiento de la ganadería en la Ciénega de Chapala (Michoacán, México). El caso de la Hacienda Guaracha (siglos XVI-XIX)”. Historelo, 6(11): 185-219.

Dirección de Comunicación Social del H. Ayuntamiento de Sahuayo, Michoacán. (2019). "El Ayuntamiento de Sahuayo y la empresa GRUENEBIZ firman convenio de colaboración 


\section{Sección Especial - Territorio, Sustentabilidad, Cultura y Transformación de Espacios}

en materia de eficiencia energética y fomento a la inversión en energías limpias." La Verdad. 29 de octubre de 2019.

González y González, L. (1979). Sahuayo. México: El Colegio Nacional.

Montes Ayala, F. G. (1991). Ensayo histórico y estadístico de Venustiano Carranza y su municipalidad. Sahuayo: H. Ayuntamiento Constitucional de Venustiano Carranza, Michoacán. 1990-1992.

Montes Ayala, F. G. (1999). Guarachita historias de otros tiempos. Sahuayo: Presidencia Municipal de Villamar, Michoacán.

Rangel M., J. L. (2005) "Transferencia de tecnología y cambio social en la Ciénaga de Chapala, siglo XXI.” En Durán, J. M., M. Sánchez y A. Escobar Ohmstede (Eds.). El Agua en la historia de México. México: Universidad de Guadalajara/El Colegio de Michoacán.

Redacción. (2017). Mundo Ejecutivo, 18 de agosto. Recuperado de: https://bit.ly/3cDyQsw

Redacción. (2018). "Listo, Complejo Administrativo y Policial Región Jiquilpan”. La Voz de Michoacán. 22 de marzo de 2018. Recuperado de: https://bit.ly/3aq17kM

Rodríguez Demorizi, E. (1971). Los Dominicos y las encomiendas de Indios de la Isla Española. Santo Domingo: Academia Dominicana de la Historia.

Sánchez Cárdenas, J. J. (2019). Entrevista. 5 de abril de 2019. Gerente Regional. Zamora, Mich. Financiera Nacional de Desarrollo Agropecuario, Rural, Forestal y Pesquero.

Sandoval Moreno, A. y Paleta Pérez, G. (2015). "La conformación de una región productiva contenciosa: el Distrito de Riego 024 Ciénega de Chapala, Michoacán, México”. Desacatos, (47): 132-149.

Tortolero, A. (2002). "Modelos europeos de aprovechamiento del paisaje agrario: la desecación de los lagos en México entre el porfiriato y la revolución”. XIII Economic History Congress. Buenos Aires, 2002. International History Association. Buenos Aires. 22-26 de julio. [Fecha de consulta: 19 de noviembre de 2006]. Recuperado de: " https://bit.ly/3bw7zYF

Vargas González, P. E. (1993). Lealtades de la sumisión. Caciquismo; poder local y regional en la Ciénega de Chápala, Michoacán. Zamora: El Colegio de Michoacán. 